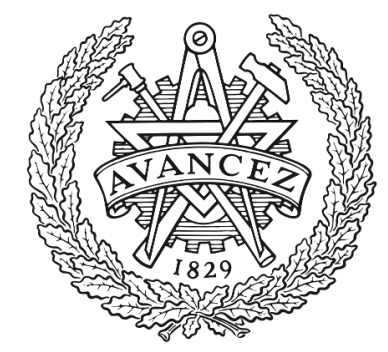

CHALMERS

UNIVERSITY OF TECHNOLOGY

\title{
Synthesis and Photophysical Characterization of Azoheteroarenes
}

Downloaded from: https://research.chalmers.se, 2023-04-26 12:07 UTC

Citation for the original published paper (version of record):

Xu, Y., Gao, C., Andreasson, J. et al (2018). Synthesis and Photophysical Characterization of Azoheteroarenes. Organic Letters, 20(16): 4875-4879. http://dx.doi.org/10.1021/acs.orglett.8b02014

N.B. When citing this work, cite the original published paper. 


\title{
Synthesis and Photophysical Characterization of Azoheteroarenes
}

\author{
Yongjin $\mathrm{Xu}{ }^{\dagger}$ Chunxia Gao, Joakim Andréasson, ${ }^{\dagger},+\odot$ and Morten Grøtli*, ${ }^{\dagger}$ \\ ${ }^{\dagger}$ Department of Chemistry and Molecular Biology, University of Gothenburg, SE-412 96 Gothenburg, Sweden \\ ${ }^{\ddagger}$ Department of Chemistry and Chemical Engineering, Physical Chemistry, Chalmers University of Technology, SE-412 96 \\ Gothenburg, Sweden
}

\section{Supporting Information}

ABSTRACT: A set of azoheteroarenes have been synthesized with Buchwald-Hartwig coupling and microwave-assisted $\mathrm{O}_{2}$ oxidation as the key steps. Several compounds exhibit good to excellent photoswitching properties (high switching efficiency, good fatigue resistance, and thermal stability of Z-isomer) relevant for photocontrolled applications, which pave the way for use in photopharmacology.

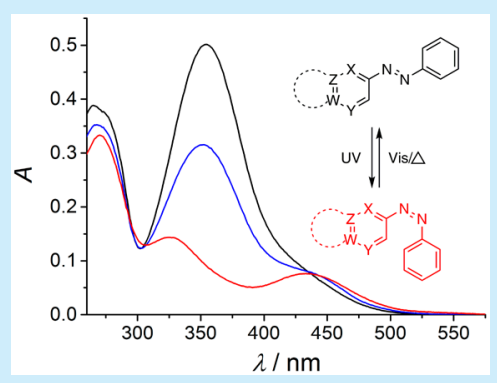

$\mathrm{P}$ hotoswitches have long held the interest of the scientific community for their ability to alter molecular structure, and thus properties, using light as a stimulus. ${ }^{1-5}$ By introducing photoswitches into bioactive molecules, their biological activities can be switched on or off upon photoisomerization between the implicated isomeric forms. ${ }^{6,7}$ In this way, photocontrolled regulators of ion channels, ${ }^{8}$ enzymes, ${ }^{9}$ receptors, ${ }^{10}$ as well as living organisms ${ }^{11}$ have been developed. Such photoresponsive molecules are powerful tools for studying living systems as they are noninvasive and offer a high spatiotemporal resolution. ${ }^{1-14}$ Azobenzene-based molecular photoswitches (Scheme 1a) have been extensively used in such developments. ${ }^{15}$ Potential future applications of this class of photoswitches include also optically controlled (bio-) materials and information/data processing to mention a few. ${ }^{16}$ Of particular interest for the latter are compounds displaying very fast thermal $Z \rightarrow E$ isomerization, allowing for ultrafast data transmission. ${ }^{17}$

Scheme 1. Photoswitches: (a) Azobenzene Photoswitches and (b) Synthetic Strategy of Azoheteroarene Molecules
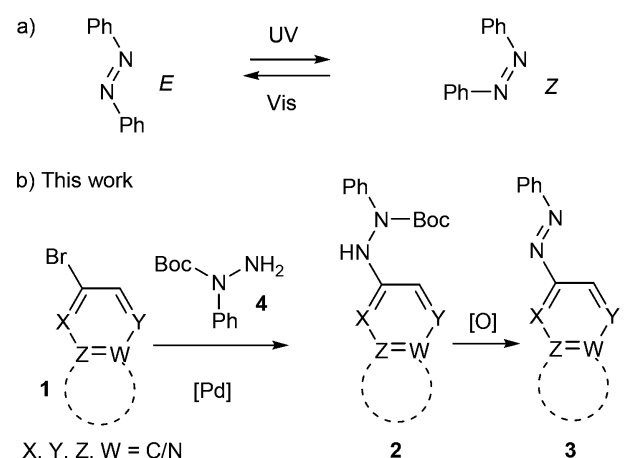

Nitrogen heterocycles are among the most significant structural components of pharmaceuticals. ${ }^{18}$ Therefore, in order to integrate the azobenzene-based molecular photoswitches into the pharmacophore of small drug-like molecules, e.g., kinase inhibitors, the development of heterocyclic azobenzene derivatives are fundamental.

Despite this fact, only a small portion of all heterocycles have been used in photoswitchable heterocyclic azoswitches. Some heterocyclic azo compounds have been well-studied, ${ }^{19-29}$ while others have been reported without mentioning photophysics/photochemistry. ${ }^{30,31}$ The classic strategies for synthesizing azobenzenes include the Azo-coupling reaction, Mills reaction, as well as metal=catalyzed coupling accompanied by oxidation. ${ }^{32}$ An efficient synthesis of red-shifted azo-benzenes was recently introduced by the coupling between ortholithiated aromatic precursors and aryldiazonium salts. ${ }^{4}$ In regard to heterocyclic azobenzene derivatives, a phenylazoimidazole, ${ }^{19}$ azoheteroarenes with methylated five-membered heterocyclic rings, ${ }^{19,28}$ including imidazoles, ${ }^{21}$ have been reported using diazonium couplings.

Herein, we report on the synthesis and the photophysical characterization of a series of azoheteroarenes, with Buchwald-Hartwig coupling or nucleophilic substitution, followed by $\mathrm{O}_{2}$ oxidation as the key synthetic steps in the preparation of the target compounds (Scheme $1 \mathrm{~b}$ ).

Pyridine and indole are among the most common aromatic heterocycles in kinase inhibitors. Therefore, we opted for the preparation of pyridine and indole-based azaanalogues, including purine and quinazoline derivatives, ${ }^{33}$ to study how the aromatic heterocycles influence the ease of synthesis and photophysical properties of azoheteroarenes. All the selected

Received: June 27, 2018

Published: August 6, 2018 
Table 1. Synthesis of Azoheteroarenes by BuchwaldHartwig Coupling and Oxidation

entry

${ }^{a}$ Using MW at $110{ }^{\circ} \mathrm{C}$, the reaction was completed in $1.5 \mathrm{~h} .{ }^{b} \mathrm{Boc}$ deprotection and oxidation combined. ${ }^{c} \mathrm{XPhos}$ was used as ligand. ${ }^{d} \mathrm{MW}, 200{ }^{\circ} \mathrm{C}, 30 \mathrm{~min} .{ }^{e} \mathrm{MW}, 180{ }^{\circ} \mathrm{C}, 1 \mathrm{~h}$, then $200{ }^{\circ} \mathrm{C}, 8 \mathrm{~min} ;{ }^{\circ} \mathrm{MW}$, $160{ }^{\circ} \mathrm{C}, 2 \mathrm{~h}$, then $180{ }^{\circ} \mathrm{C}, 30 \mathrm{~min}$.

target compounds contain heterocycles that are found in reported kinase inhibitors $(\mathbf{1} \mathbf{a}-\mathbf{1 h}$; Table 1$)$.

Bromoheterocycles 1a-1d (entries 1-3; Scheme 1) were initially tested out using Buchwald-Hartwig conditions. ${ }^{34}$ Both 1a, 1b, and $\mathbf{1 d}$ substrates gave the target coupling products $\mathbf{2 a}, \mathbf{2 b}$, and $\mathbf{3 d}$ in good yields. However, $\mathbf{1 c}$ underwent significant reduction of the aryl halide by $\beta$ elimination $^{35}$ during the coupling, ${ }^{36}$ and only a low yield of $2 \mathrm{c}$ was obtained.

However, when 1e was submitted to this condition, no product formation was observed. This was probably because the secondary amine in the heterocycle interfered with the coupling reaction. Therefore, we decided to block the function of the secondary amine with an appropriate protecting group. The Boc group could be installed on 5-bromoindole efficiently, but the Boc group was cleaved under the coupling conditions. Instead, we turned to tosyl, and 1e-2, 1f-2, 1g-2, and 1h-2 could be obtained in good to excellent yields (see Supporting Information (SI)). ${ }^{37}$ When $\mathbf{1 f - 2}$ and $\mathbf{1 g - 2}$ (entries 6 and 7, Table 1) were treated under standard Buchwald-Hartwig coupling conditions, $\mathbf{2} \mathbf{e}-\mathbf{2 g}$ were obtained in good yield (above $80 \%$ ). However, the tosyl group on $\mathbf{1 h}-\mathbf{2}$ was unstable under these conditions. Compound $\mathbf{l h}$ was therefore protected with $\mathrm{THP}^{38}$ to give $\mathbf{1 h}-\mathbf{3}$ (entry 8 , Table 1 ) and then subjected to the coupling condition to generate $2 \mathrm{~h}$ in $42 \%$ isolated yield (data not shown). When XPhos was employed as the ligand instead of $t-\mathrm{Bu}_{3} \mathrm{P} \cdot \mathrm{HBF}_{4}$, the reaction completed and provided coupling product $3 \mathrm{~h}$ with a yield of $54 \%$.

Inspired by work from the groups of Szymanski and Feringa, ${ }^{22}$ we aimed at forming the azo bond with a "onepot, two-steps strategy", more specifically, removing the Boc group by microwave-assisted heating (above $150{ }^{\circ} \mathrm{C}$ ) ${ }^{39}$ and then oxidizing the hydrazine to give azo products with $\mathrm{O}_{2}$. Several rounds of optimization resulted in a protocol giving generally excellent yields (Table 1).

The tosyl group on $3 \mathbf{e}-\mathbf{3 g}$ could be removed by $\mathrm{Cs}_{2} \mathrm{CO}_{3}{ }^{40}$ to give the corresponding heterocyclic azoarenes $(\mathbf{5 e}-\mathbf{5 g}$; see SI) with a yield above $80 \%$. The THP group on $3 \mathbf{h}$ was deprotected by $4 \mathrm{M} \mathrm{HCl}$ in dioxane $\mathrm{M}^{39}$ to provide $\mathbf{5 h}$ in $74 \%$ yield.

Applying our developed Pd-mediated coupling strategy to 6$\mathrm{Cl}-9 \mathrm{H}$-purine (1i) and 4-Cl-quinazoline (1j) gave no detectable coupling products (see SI). Therefore, we turned to take nucleophilic substitution as the key step. ${ }^{41-44}$ Compound $1 \mathrm{i}$ in $n$-BuOH, under an $\mathrm{N}_{2}$ atmosphere, was treated with phenylhydrazine in the presence of DIPEA, using microwave heating $\left(150{ }^{\circ} \mathrm{C}, 2 \mathrm{~h}\right)^{22}$ followed by $\mathrm{O}_{2}$ treatment to form the azo compound $\mathbf{6}$ (see SI) in $65 \%$ yield. When $\mathbf{1 j}$ was treated with the same condition, no target product was detected by LC-MS or ${ }^{1} \mathrm{H}$ NMR. However, when changing from $n-\mathrm{BuOH}$ to $i-\mathrm{PrOH}$ as solvent ${ }^{42}$ and heating at a lower temperature ( $\mathrm{MW} 60{ }^{\circ} \mathrm{C}, 30 \mathrm{~min}$ ), followed by the $\mathrm{O}_{2}$ treatment, 8 was obtained in moderate yield (23\%; see SI).

The photophysical properties of $\mathbf{3 a - 8}$ were then characterized. The experimental results are shown only for $\mathbf{5 e}$ (Figure 1a, see SI for "enlarged" versions of all absorption spectra), whereas the evaluated photophysical parameters for the whole series are collected in Table 2. Water/DMSO has been used as solvent. When the heterocyclic azo-switches get integrated with phramacophores, water solubility could increase, thereby excluding or minimizing the need of DMSO as cosolvent.

The initial absorption spectra, ascribed to $100 \%$ E-isomer, were recorded after thermal adaption at $50{ }^{\circ} \mathrm{C}$ for $72 \mathrm{~h}$. The absorption maxima of the $\pi \rightarrow \pi^{*}$ transition for the respective compounds are observed at $\lambda$ between 317 and $387 \mathrm{~nm}$, whereas the $\mathrm{n} \rightarrow \pi^{*}$ transitions at longer wavelengths are very weak and barely seen in the absorption spectra. There is a clear trend for the $\pi \rightarrow \pi^{*}$ transition to redshift with increasing size of the heterocycle. Leaving aside the protected compounds $(3 \mathbf{e}-3 \mathbf{h})$ the monocyclic compounds display absorption maxima between 317 and $328 \mathrm{~nm}$, the bicyclic between 325 and $362 \mathrm{~nm}$, and the tricyclic at $387 \mathrm{~nm}$.

Introduction of the electron-withdrawing tosyl group results in a blue shift of the absorption maxima (cf. $3 \mathbf{e}-\mathbf{3 g}$ and $5 \mathbf{e}-$ $\mathbf{5 g}$ ) as well as significant hyperchromism (see absorption 
Table 2. Photophysical Properties

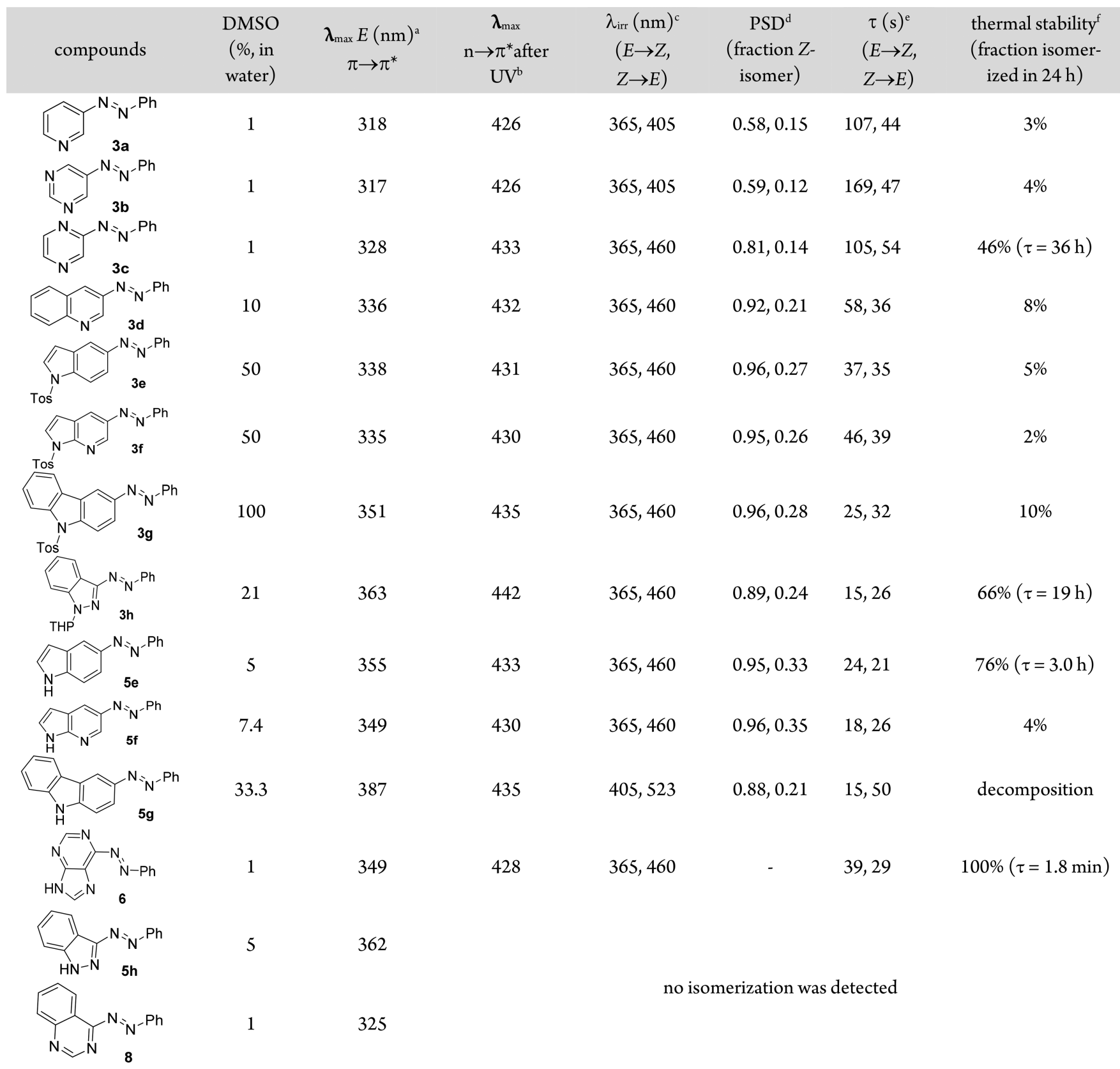

${ }^{a}$ Wavelengths of the $\pi \rightarrow \pi^{*}$ transition of the $E$-isomer. ${ }^{b} \lambda_{\max }$ in the $\mathrm{n} \rightarrow \pi^{*}$ region at the photostationary distribution (PSD) after UV irradiation. ${ }^{c}$ Irradiation wavelengths used to enrich the samples in the $Z$ - (longer wavelength light) and $E$-isomers (shorter wavelength light), respectively. ${ }^{d}$ Photostationary distribution after photoisomerization to enrich the samples in the $Z$ - and $E$-isomers, respectively. Tabulated as the fraction of the $Z$-isomer. Determined in pure DMSO- $d_{6}{ }^{e}$ Time constants for the photoisomerization reactions, normalized to a common light density ( $365 \mathrm{~nm}$ : $2.5 \mathrm{~mW} / \mathrm{cm}^{2}, 405 \mathrm{~nm}: 4.0 \mathrm{~mW} / \mathrm{cm}^{2}, 460 \mathrm{~nm}: 3.0 \mathrm{~mW} / \mathrm{cm}^{2}$ ). See SI for the original conditions used. ${ }^{f}$ Fraction of the sample isomerized in the thermal $Z \rightarrow E$ reaction over $24 \mathrm{~h}$. When isomerization is substantial, the corresponding time constant of the reaction is given.

spectra in the SI). Electron donation from a THP group (cf. $3 \mathbf{h}$ and $\mathbf{5 h}$ ) also results in hyperchromism but has no effect on the spectral position. The spectral shifts are supported by quantum mechanical (DFT) calculations (see SI). Subsequent exposure to UV light resulted in an increased absorption of the $\mathrm{n} \rightarrow \pi^{*}$ transition at the expense of the $\pi \rightarrow \pi^{*}$ transition. All processes proceeded with isosbestic points, which implies clean conversion between the two implicated isomers. The wavelengths of the absorption maxima in the $\mathrm{n} \rightarrow \pi^{*}$ region are collected in Table 2, together with the isomerization kinetics and the photostationary distribution (PSD). Although no attempts were made toward determining the isomerization quantum yields, it is seen that the $E \rightarrow Z$ isomerizations readily proceed at the modest light intensities used in the experiments $\left(2-4 \mathrm{~mW} / \mathrm{cm}^{2}\right)$. At the PSD, samples $\mathbf{3 a}-\mathbf{5 g}$ are enriched in the $Z$-form to between ca. $60 \%$ and almost full conversion. Compounds $\mathbf{5 h}$ and $\mathbf{8}$ showed no detectable isomerization (see below), while the thermal reversion for 6 was too fast to allow for the determination of any reliable value.

Note that the PSDs were assessed in pure DMSO (Figure 1b) as opposed to water/DMSO. The values should, however, be similar for the two solvent systems (Figure S39). 
a)
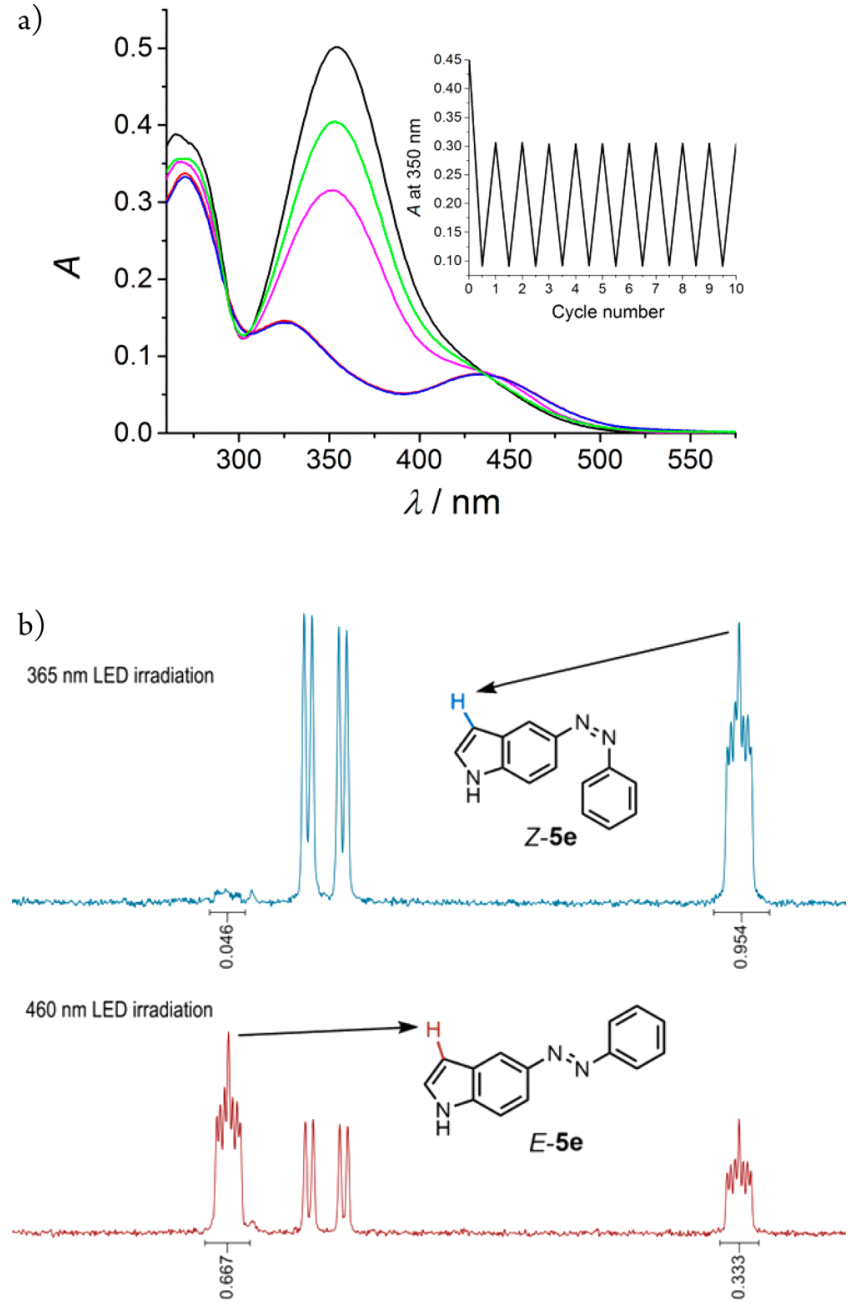

Figure 1. (a) Absorption spectra of compound 5e at $30 \mu \mathrm{M}$ concentration in aqueous solution ( $5 \% \mathrm{DMSO}$ ). Black line: At thermal equilibrium. Red line: After exposure to $365 \mathrm{~nm} \mathrm{UV}$ to yield the PSD. Magenta line: After exposure to $405 \mathrm{~nm}$ light to yield the PSD. Blue line: After a second round of $365 \mathrm{~nm}$ UV to yield the PSD. Green line: Spectra recorded $24 \mathrm{~h}$ (at room temperature in the dark) subsequent to the second round of $365 \mathrm{~nm}$ UV. The inset shows the absorption changes during 10 cycles of UV and Vis exposure. (b) ${ }^{1} \mathrm{H}$ NMR spectra of $5 \mathbf{e}$ at the PSD after exposure to $365 \mathrm{~nm}$ light and 460 $\mathrm{nm}$ light allowing quantification of $Z / E$ ratios.

The majority of the compounds displays good thermal stability, as less than $10 \%$ is isomerized back to the $E$ - form after $24 \mathrm{~h}$ in the dark. Exceptions are 3c, 3g, 3h, 5e, and 6 (Table 2). Compound $\mathbf{5 g}$ decomposes rapidly, tentatively ascribed to hydrolysis. With the exception of $\mathbf{6}$, these are the compounds with the lowest activation energies for thermal $Z$ $\rightarrow E$ isomerization as estimated by DFT calculations assuming thermal isomerization through inversion ${ }^{28,45}$ (see SI). The discrepancy for $\mathbf{6}$ is tentatively ascribed to a different isomerization mechanism, rotation rather than inversion, as $\mathbf{6}$ together with $\mathbf{8}$ in the $Z$-form display the largest twisting angles between the plane of the heterocycle and the $\mathrm{N}-\mathrm{N}$ double bond (see SI).

Compounds $5 \mathrm{~h}$ and $\mathbf{8}$ were subjected to ns transient absorption measurements. After the excitation pulse at 355 or $410 \mathrm{~nm}$, the ground-state bleach recovery in the $\pi \rightarrow \pi^{*}$ region was monitored and found to contain no detectable transients. Thus, the only thing we can conclude is that if the absence of detectable $Z$-isomers is due to thermal isomeriation $Z \rightarrow E$ it must be faster than the time resolution of the experiment, i.e., a few nanoseconds.

The photoinduced $Z \rightarrow E$ isomerizations were studied by exposing the samples enriched in the $Z$-form to light in the visible region, yielding PSD containing between $65 \%$ and $88 \%$ of the $E$-isomer. The rates at which the isomerizations occur show efficient isomerization already at moderate light intensities $\left(1-4 \mathrm{~mW} / \mathrm{cm}^{2}\right)$. Except for $3 \mathrm{f}$, no significant photodecomposition was observed upon photocycling (Figures S15-S26).

In conclusion, we have synthesized a set of azoheteroarenes mainly with a strategy using Buchwald-Hartwig coupling and $\mathrm{O}_{2}$ oxidation as the key steps and commercially available heterocyclic halogen as the starting substrates. The majority of the compounds can be enriched in the $Z$-isomer to more than $90 \%$ using light at 365 or $405 \mathrm{~nm}$, whereas the reverse photoisomerization yields between $65 \%$ and $85 \%$ E-isomer at the photostationary state using longer wavelength of light. The thermal stability of the $Z$-isomer ranges between minutes to months, and nearly all compounds have excellent photostability. The relatively easy availability by synthesis together with favorable photophysical properties make some of these compounds promising candidates for future application in photopharmacology, e.g., photoswitchable kinase inhibitors.

\section{ASSOCIATED CONTENT}

\section{Supporting Information}

The Supporting Information is available free of charge on the ACS Publications website at DOI: 10.1021/acs.orglett.8b02014.

Experimental procedures and UV-vis and NMR spectra (PDF)

\section{AUTHOR INFORMATION}

\section{Corresponding Authors}

*E-mail: a-son@chalmers.se.

*E-mail: grotli@chem.gu.se.

ORCID $\odot$

Joakim Andréasson: 0000-0003-4695-7943

Morten Grøtli: 0000-0003-3621-4222

\section{Notes}

The authors declare no competing financial interest.

\section{ACKNOWLEDGMENTS}

This work was supported by the Swedish Research Council (VR, grant No. 2015-05642 for M.G. and 2016-0360 for J.A.). We thank Astrid Nilsen-Moe, Department of ChemistryÅngström Laboratory, Uppsala University, for valuable assistance with the ns transient absorption measurements.

\section{REFERENCES}

(1) Molecular Switches; Feringa, B. L., Browne, W. R., Eds.; WileyVCH: Weinheim, 2011.

(2) Dong, M.; Babalhavaeji, A.; Samanta, S.; Beharry, A. A.; Woolley, G. A. Acc. Chem. Res. 2015, 48, 2662.

(3) Russew, M.-M.; Hecht, S. Adv. Mater. 2010, 22, 3348.

(4) Hansen, M. J.; Lerch, M. M.; Szymanski, W.; Feringa, B. L. Angew. Chem., Int. Ed. 2016, 55, 13514.

(5) Bléger, D.; Hecht, S. Angew. Chem., Int. Ed. 2015, 54, 11338. 
(6) Velema, W. A.; Szymanski, W.; Feringa, B. L. J. Am. Chem. Soc. 2014, 136, 2178.

(7) Li, G.; Ma, L.; Liu, G.; Fan, C.; Pu, S. RSC Adv. 2017, 7, 20591.

(8) Banghart, M.; Borges, K.; Isacoff, E. Y.; Trauner, D.; Kramer, R.

H. Nat. Neurosci. 2004, 7, 1381.

(9) Ferreira, R.; Nilsson, J. R.; Solano, C.; Andréasson, J.; Grøtli, M. Sci. Rep. 2015, 5, 09769.

(10) Kienzler, M. A.; Reiner, A.; Trautman, E.; Yoo, S.; Trauner, D.; Isacoff, E. Y. J. Am. Chem. Soc. 2013, 135, 17683.

(11) Al-Atar, U.; Fernandes, R.; Johnsen, B.; Baillie, D.; Branda, N. R. J. Am. Chem. Soc. 2009, 131, 15966.

(12) Velema, W. A.; van der Berg, J. P.; Hansen, M. J.; Szymanski, W.; Driessen, A. J. M.; Feringa, B. L. Nat. Chem. 2013, 5, 924.

(13) Polosukhina, A.; Litt, J.; Nemargut, J.; Sychev, Y.; Trauner, D.; Van Gelder, R. N.; Kramer, R. H. Neuron 2012, 75, 271.

(14) Gorostiza, P.; Isacoff, E. Y. Science 2008, 322, 395.

(15) Szymanski, W.; Beierle, J. M.; Kistemaker, H. A. V.; Velema, W. A.; Feringa, B. L. Chem. Rev. 2013, 113, 6114.

(16) (a) Gelebart, A. H.; Mulder, D. J.; Varga, M.; Konya, A.; Vantomme, G.; Meijer, E. W.; Selinger, R. L. B.; Broer, D. J. Nature 2017, 546, 632. (b) Zhang, J.; Wang, J.; He, T. Mater. Horiz. 2014, 1, 169. (c) Göstl, R.; Senf, A.; Hecht, S. Chem. Soc. Rev. 2014, 43, 1982. (d) Erbas-Cakmak, S.; Kolemen, S.; Sedgwick, A. C.; Gunnlaugsson, T.; James, T. D.; Yoon, J.; Akkaya, E. U. Chem. Soc. Rev. 2018, 47, 2228.

(17) Garcia-Amorós, J.; Cuadrado, A.; Reig, A.; De Waele, V.; Poizat, O. Chem. - Eur. J. 2015, 21, 14292.

(18) Vitaku, E.; Smith, D. T.; Njardarson, J. T. J. Med. Chem. 2014, $57,10257$.

(19) Wendler, T.; Schütt, C.; Näther, C.; Herges, R. J. Org. Chem. 2012, 77, 3284.

(20) Weston, C. E.; Richardson, R. D.; Haycock, P. R.; White, A. J. P.; Fuchter, M. J. J. Am. Chem. Soc. 2014, 136, 11878.

(21) Weston, C. E.; Richardson, R. D.; Fuchter, M. J. Chem. Commun. 2016, 52, 4521.

(22) Kolarski, D.; Szymanski, W.; Feringa, B. L. Org. Lett. 2017, 19, 5090.

(23) Whittaker, N.; Jones, T. S. G J. Chem. Soc. 1951, 1565.

(24) Ragon, F.; Yaksi, K.; Sciortino, N. F.; Chastanet, G.; Kepert, C. J.; Neville, S. M.; et al. Aust. J. Chem. 2014, 67, 1563.

(25) Wang, Y.-T.; Liu, X.-Y.; Cui, G.; Fang, W.-H.; Thiel, W. Angew. Chem., Int. Ed. 2016, 55, 14009.

(26) Otsuki, J.; Suwa, K.; Sarker, K.-K.; Sinha, C. J. Phys. Chem. A 2007, 111, 1403.

(27) Simeth, N. A.; Crespi, S.; Fagnoni, M.; König, B. J. Am. Chem. Soc. 2018, 140, 2940.

(28) Calbo, J.; Weston, C. E.; White, A. J. P.; Rzepa, H. S.; Contreras-García, J.; Fuchter, M. J. J. Am. Chem. Soc. 2017, 139, 1261.

(29) Stricker, L.; Fritz, E.-C.; Peterlechner, M.; Doltsinis, N. L.; Ravoo, B. J. J. Am. Chem. Soc. 2016, 138, 4547.

(30) Brown, E. V. J. Heterocycl. Chem. 1969, 6, 571.

(31) Kyziol, J. B. J. Heterocycl. Chem. 1985, 22, 1301.

(32) Merino, E. Chem. Soc. Rev. 2011, 40, 3835.

(33) Sharma, V.; Kamal, R.; Kumar, V. Curr. Top. Med. Chem. 2017, $17,2482$.

(34) Lim, Y.-K.; Lee, K. S.; Cho, C. G. Org. Lett. 2003, 5, 979.

(35) Muci, A. R.; Buchwald, S. L. Top. Curr. Chem. 2002, 219, 131.

(36) When 1c was stirred at $100{ }^{\circ} \mathrm{C}$ under microwave or normal heating, an isomer of $2 \mathrm{c}$ was obtained as $\mathbf{2 c - 2}$ (see SI); when this byproduct was heated at $120-150{ }^{\circ} \mathrm{C}$, it converted back to $2 \mathrm{c}$.

(37) Belliotti, T. R.; Wustrow, D. J.; Brink, W. A.; Zoski, K. T.; Shih, Y.-H.; Whetzel, S. Z.; Georgic, L. M.; Corbin, A. E.; Akunne, H. C.; Heffner, T. G.; Pugsley, T. A.; Wise, L. D. J. Med. Chem. 1999, 42, 5181.

(38) Lohou, E.; Collot, V.; Stiebing, S.; Rault, S. Synthesis 2011, 16, 2651.

(39) Hasan, I.; Marnelli, E. R.; Lin, L. C.; Fowler, F. W.; Levy, A. B. J. Org. Chem. 1981, 46, 157.
(40) Bajwa, J. S.; Chen, G.-P.; Prasad, K.; Repic, O.; Blacklock, T. J. Tetrahedron Lett. 2006, 47, 6425.

(41) Rooney, L.; Vidal, A.; D'Souza, A. M.; Devereux, N.; Masick, B.; Boissel, V.; West, R.; Head, V.; Stringer, R.; Lao, J.; Petrus, M. J.; Patapoutian, A.; Nash, M.; Stoakley, N.; Panesar, M.; Verkuyl, J. M.; Schumacher, A. M.; Petrassi, H. M.; Tully, D. C. J. Med. Chem. 2014, 57, 5129.

(42) Van Horn, K. S.; Burda, W. N.; Fleeman, R.; Shaw, L. N.; Manetsch, R. J. Med. Chem. 2014, 57, 3075.

(43) Mantione, D.; Aizpuru, O. O.; Memeo, M. G.; Bovio, B.; Quadrelli, P. Eur. J. Org. Chem. 2016, 2016, 983.

(44) Too, K.; Brown, D. M.; Bongard, E.; Yardley, V.; Vivasb, L.; Loakes, D. Bioorg. Med. Chem. 2007, 15, 5551.

(45) Yin, T. T.; Zhao, Z.-X.; Zhang, H. X. New J. Chem. 2017, 41, 1659. 